\title{
Distribution of blood flow in the ovary of domestic fowl (Gallus domesticus) and changes after prostaglandin F-2 $\alpha$ treatment
}

\author{
C. G. Scanes, H. Mozelic, E. Kavanagh, G. Merrill and J. Rabii \\ Department of Physiology and Bureau of Biological Research, Rutgers-The State University, \\ New Brunswick, New Jersey 08903, U.S.A.
}

\begin{abstract}
Summary. Radioactive microspheres $\left({ }^{14} \mathrm{Ce}\right.$ - and ${ }^{46} \mathrm{Sc}$-labelled) were used to show that the 5 major pre-ovulatory follicles receive about half of the ovarian blood flow. A progressive increase in the blood flow to these pre-ovulatory follicles during their maturation was observed. Blood flow to the post-ovulatory follicles was low. The administration of PGF- $2 \alpha$ was followed by a consistent decrease in blood flow to the major pre-ovulatory follicles.
\end{abstract}

\section{Introduction}

The flow of blood to the tissues of the mammalian ovary varies with the physiological state of the animal. In the guinea-pig, for instance, blood flow to the corpus luteum, as estimated by the accumulation of radioactively labelled microspheres in capillaries, is decreased before luteolysis (Wehrenberg, Dierschke, Rankin \& Wolf, 1978). Similarly, blood flow to the corpus luteum of the ewe is increased during the early luteal phase and subsequently falls during the late luteal phase of the cycle (Niswender, Reimers, Diekman \& Nett, 1976). Moreover, a positive correlation exists between blood flow to the ovary and plasma concentrations of progesterone, and blood flow to the corpus luteum and its ability to bind radioiodinated human chorionic gonadotrophin (Niswender et al., 1976).

There is evidence that prostaglandin (PG) F-2 $\alpha$, which induces luteolysis in some animals, also decreases blood flow to the ovary or corpus luteum (rat: Pharriss, Cornette \& Gutknecht, 1970; rabbit: Pharriss et al., 1970; Novy \& Cook, 1973; dog: Varga \& Folly, 1977; sheep: Nett, McClellan \& Niswender, 1976; Niswender et al., 1976; O'Shea, Nightingale \& Chamley, 1977) but this does not occur in the guinea-pig (Wehrenberg, Dierschke \& Wolf, 1979).

With the exception of a single study there is relatively little information on the blood flow within the ovary of the domestic hen (Wolfenson, Berson, Frei \& Snapir, 1978). We therefore studied blood flow within the ovary of the chicken and examined the effects of PGF-2 $\alpha$ on this blood flow because PGF-2 $\alpha$ is produced by the largest preovulatory follicle in chicken (Day \& Nalbandov, 1977; Hammond, Olson, Frenkel, Biellier \& Hertelendy, 1981a) and turkey (Hammond, Koelkebeck, Scanes, Biellier \& Hertelendy, 1981b).

\section{Materials and Methods}

White Leghorn hens (weighing approximately $1.2 \mathrm{~kg}$ ) were lightly anaesthetized with pentobarbitone sodium $(0.5 \mathrm{ml})$. The birds had previously been maintained in a photoperiod of $14 \mathrm{~h} \mathrm{light} / 24 \mathrm{~h}$ and had free access to food and water. The hens were used between 0 and $6 \mathrm{~h}$ after oviposition and ovulation. 
Blood flow to the ovary was determined using radioactive microspheres by the method developed for the chicken (Merrill, Russo \& Halper, 1981). Briefly, this entailed implanting heparinized saline-filled polyethylene cannulas (PE 50) (Clay Adams, Parsippany, New Jersey) into the left brachial artery and the right carotid artery. The carotid cannula was advanced into the left ventricle (as determined by the ventricular pressure wave form). Birds then received intraventricular injections of ${ }^{141}$ Ce-labelled microspheres $\left(>2.5 \times 10^{5}, 15 \mu \mathrm{m}\right.$ : New England Nuclear, Boston, Massachusetts) in $0.3 \mathrm{ml}$ suspension in a $10 \%$ dextran solution containing Tween 80. Brachial arterial blood was withdrawn during the intraventricular injection. This allows determination of cardiac output (withdrawal rate $\times$ total activity of spheres injected/activity of withdrawn sample). The birds were then immediately given an intra-arterial bolus injection of 100 $\mu \mathrm{g}$ FSH (NIH-FSH-S11), $100 \mu \mathrm{g}$ PGF-2 $\alpha$ (Sigma, St Louis, Missouri) or saline vehicle $(9 \mathrm{~g}$ $\mathrm{NaCl} / \mathrm{l})$. After $10 \mathrm{~min}$, a second injection of $>40000{ }^{46} \mathrm{Sc}$-labelled microspheres $(15 \mu \mathrm{m}$ : New England Nuclear) was given. Cardiac output was again determined. After approximately $10 \mathrm{~min}$ the birds were killed and the ovary and oviduct removed. The ovary was dissected to provide the five largest pre-ovulatory follicles, the first post-ovulatory follicle, the other post-ovulatory follicles, the small follicles containing yellow yolk, the small follicles (diameter $<1 \mathrm{~mm}$ ) containing white yolk and the rest of the ovary (stroma and very small follicles).

Yolk was removed from the five major follicles because it contained less than $0.1 \%$ of the radioactivity (spheres) in the ovary. The ovarian tissues were then weighed and their ${ }^{141} \mathrm{Ce}$ and ${ }^{46} \mathrm{Sc}$ activities determined in an automated gamma counter (Beckman 4000). Sample tissues from the oviduct (infundibulum, magnum, isthmus and uterus) were similarly weighed and their ${ }^{141} \mathrm{Ce}$ and ${ }^{46} \mathrm{Sc}$ activities estimated.

Blood flow to the selected reproductive organs was expressed as percentage of the blood flow to the ovary, percentage of the cardiac output (\% C. O.), \% C. O. per gram tissue weight, actual volume of flow to the tissue $(\mu \mathrm{l} / \mathrm{min})$ and actual volume of flow per gram tissue weight. Data were analysed by a paired $t$ test or analysis of variance as appropriate.

\section{Results}

The distribution of blood flow within the ovarian tissues is shown in Table 1. Blood flow was greatest to the five major pre-ovulatory follicles (representing $48 \cdot 2 \%$ of total ovarian blood flow) and the flow to all the follicular tissues represented $>83.6 \%$ of the total ovarian blood flow. Blood flow values increased with the maturation of the pre-ovulatory follicles but that to the

Table 1. Distribution of blood flow to the ovary of the hen by ${ }^{141} \mathrm{Ce}-$ labelled microspheres

\begin{tabular}{lc}
\hline \multicolumn{1}{c}{ Tissue } & \% distribution of blood flow \\
\hline Small white follicles ( $>1 \mathrm{~mm}$ diameter) & $17.0 \pm 1.7(19)$ \\
Small yellow follicles & $12.6 \pm 1.8(19)$ \\
Pre-ovulatory follicles & $3.9 \pm 0.5(16)$ \\
$\mathrm{C}_{5}$ & $6.1 \pm 0.7(18)^{*}$ \\
$\mathrm{C}_{4}$ & $8.4 \pm 0.8(19)^{*}$ \\
$\mathrm{C}_{3}$ & $12.4 \pm 1.0(19)^{* * *}$ \\
$\mathrm{C}_{2}$ & $17.4 \pm 1.6(19)^{* *}$ \\
$\mathrm{C}_{1}$ & $5.2 \pm 0.6(19)^{* * *}$ \\
First post-ovulatory follicle & $3.6 \pm 0.8(11)$ \\
Other post-ovulatory follicles & $16.4 \pm 1.7(18)$ \\
Rest of ovary & \\
\hline
\end{tabular}

Values are mean \pm s.e.m. for the no. of observations in parentheses.

Values significantly different from preceding value (paired $t$ test):

${ }^{*} P<0.05,{ }^{* *} P<0.02,{ }^{* * *} P<0.001$. 
post-ovulatory follicle fell sharply (to $29.9 \%$ of that observed in the largest $\left(C_{1}\right)$ pre-ovulatory follicle).

The effects of PGF-2 $\alpha$ and FSH on the intra-ovarian distribution of blood flow are shown in Table 2. FSH had no effect on blood flow, but there was a significant fall in blood flow to the pre-ovulatory follicles in PGF- $2 \alpha$-treated hens $\left(49 \%\right.$ for $\mathrm{C}_{5}, 67 \%$ for $\mathrm{C}_{4}, 44 \%$ for $\mathrm{C}_{3}, 38 \%$ for $\mathrm{C}_{2}$ and $47 \%$ for $\mathrm{C}_{1}$ follicles). Some increase in blood flow to the post-ovulatory follicle, ovarian stroma and small white follicles was also observed. The effects of PGF-2 $\alpha$ on blood flow were further examined by comparison of blood flow before (determined using ${ }^{141} \mathrm{Ce}$-labelled microspheres) and after (determined by ${ }^{46} \mathrm{Sc}$-labelled microspheres) PGF-2 $\alpha$ injection.

Table 2. Effect of prostaglandin F-2 $\alpha$ and FSH on blood flow in the ovary of the hen determined with ${ }^{46} \mathrm{Sc}$-labelled microspheres

\begin{tabular}{|c|c|c|c|}
\hline \multirow[b]{2}{*}{ Tissue } & \multicolumn{3}{|c|}{ Blood flow (as \% of flow to ovary) } \\
\hline & Saline control & PGF- $2 \alpha$ & FSH \\
\hline Small white follicles $(>1 \mathrm{~mm})$ & $14.0 \pm 3.6(7)$ & $22 \cdot 5 \pm 2 \cdot 3(6)$ & $16 \cdot 5 \pm 3 \cdot 7(7)$ \\
\hline Small yellow follicles & $14.9 \pm 3.2(7)$ & $15 \cdot 2 \pm 6 \cdot 1(7)$ & $16.0 \pm 1.8(7)$ \\
\hline \multicolumn{4}{|l|}{ Pre-ovulatory follicles } \\
\hline $\mathrm{C}_{5}$ & $5 \cdot 1 \pm 1 \cdot 1(5)$ & $2.6 \pm 0.4(6)^{*}$ & $3.8 \pm 0.8(4)$ \\
\hline$C_{4}$ & $6.7 \pm 1.6(6)$ & $2.2 \pm 0.6(6)^{* *}$ & $7.9 \pm 0.5(6)$ \\
\hline $\mathrm{C}_{3}$ & $8.1 \pm 0.9(7)$ & $4 \cdot 5 \pm 1 \cdot 1(6)^{*}$ & $8 \cdot 1 \pm 1 \cdot 2(7)$ \\
\hline $\mathrm{C}_{2}$ & $12 \cdot 6 \pm 1 \cdot 6(7)$ & $7.8 \pm 2.0(7)^{*}$ & $12 \cdot 5 \pm 1 \cdot 1(7)$ \\
\hline$C_{1}$ & $13.9 \pm 2 \cdot 2(7)$ & $7 \cdot 3 \pm 1.6(6)^{*}$ & $13.5 \pm 1.5(7)$ \\
\hline First post-ovulatory follicle & $4.0 \pm 1.2(6)$ & $8.0 \pm 1.9(6)^{*}$ & $6.1 \pm 0.8(7)$ \\
\hline Rest of ovary & $18 \cdot 9 \pm 3 \cdot 6(7)$ & $34 \cdot 3 \pm 5 \cdot 5(5)^{*}$ & $14 \cdot 7 \pm 2 \cdot 0(7)$ \\
\hline
\end{tabular}

Values are mean \pm s.e.m. for the no. of observations in parentheses.

Values significantly different from saline control value (ANOVA): $P<0.05,{ }^{* *} P<0.01$.

These data are shown in Tables 3 and 4 . Blood flow to the 5 major follicles was again decreased by PGF- $2 \alpha$ administration and the fall was significant $(P<0.05)$ for the $\mathrm{C}_{1}$ and $\mathrm{C}_{2}$ follicles irrespective of whether expressed as a percentage of cardiac output, actual flow, \% cardiac output per $\mathrm{g}$ tissue or actual flow per $\mathrm{g}$ tissue. The effect of PGF-2 $\alpha$ was significant $(P<0.05)$ for the $C_{3}$ and $C_{4}$ follicles when expressed as a $\%$ cardiac output or \% cardiac output per $\mathrm{g}$ tissue. The differences in these data depending on how they are expressed are due

Table 3. Effect of prostaglandin F-2 $\alpha$ on blood-flow in the ovary of the hen

\begin{tabular}{lcc}
\hline & \multicolumn{2}{c}{ Blood flow $(\mathrm{ml} / \mathrm{min})$} \\
\cline { 2 - 3 } Tissue & Before treatment & $10 \mathrm{~min}$ after PGF-2a \\
\hline Small white follicle & $0.51 \pm 0.19$ & $0.43 \pm 0.12$ \\
Small yellow follicles & $0.24 \pm 0.04$ & $0.48 \pm 0.31$ \\
Pre-ovulatory follicles & & \\
$\mathrm{C}_{5}$ & $0.20 \pm 0.07$ & $0.05 \pm 0.02$ \\
$\mathrm{C}_{4}$ & $0.20 \pm 0.06$ & $0.05 \pm 0.02^{*}$ \\
$\mathrm{C}_{3}$ & $0.34 \pm 0.14$ & $0.12 \pm 0.04$ \\
$\mathrm{C}_{2}$ & $0.47 \pm 0.12$ & $0.18 \pm 0.05^{*}$ \\
$\mathrm{C}_{1}$ & $0.43 \pm 0.09$ & $0.19 \pm 0.07^{* * *}$ \\
First post-ovulatory follicle & $0.15 \pm 0.05$ & $0.10 \pm 0.03$ \\
Rest of ovary & $0.52 \pm 0.20$ & $0.39 \pm 0.13$ \\
\hline
\end{tabular}

Values are mean \pm s.e.m. for 4 observations.

Values significantly different from pre-treatment value (paired $t$ test):

${ }^{*} P<0.05 ;{ }^{* * *} P<0.01$. 
largely to the differences in variance. The pattern of pre-treatment blood flow within the ovary (Table 3) was similar to that indicated in Tables 1 and 2. There was little difference between blood flow to the major follicles when expressed relative to tissue weight (Table 4). There was some evidence for increase blood flow to the uterus after PGF-2 $\alpha$ treatment (Table 4).

Table 4. Blood flow in the ovary and oviduct of the hen before and $10 \mathrm{~min}$ after treatment with prostaglandin F-2 $\alpha$

\begin{tabular}{|c|c|c|c|c|}
\hline \multirow[b]{2}{*}{ Tissue } & \multicolumn{2}{|c|}{$\%$ Cardiac output per $\mathrm{g}$} & \multicolumn{2}{|c|}{$\mathrm{ml} / \mathrm{min} / \mathrm{g}$} \\
\hline & Pre-treatment & Post-treatment & Pre-treatment & Post-treatment \\
\hline Small white follicle & $0.12 \pm 0.02(5)$ & $0.19 \pm 0.07(5)$ & $0.57 \pm 0.22(4)$ & $0.54 \pm 0.23(4)$ \\
\hline Small yellow follicle & $0.06 \pm 0.02(5)$ & $0.09 \pm 0.05$ & $0.23 \pm 0.08$ & $0.26 \pm 0.17(4)$ \\
\hline \multicolumn{5}{|l|}{ Pre-ovulatory follicles } \\
\hline $\mathrm{C}_{5}$ & $0.33 \pm 0.06(5)$ & $0.17 \pm 0.04(5)$ & $1.47 \pm 0.48(4)$ & $0.39 \pm 0.13(4)$ \\
\hline $\mathrm{C}_{4}$ & $0.20 \pm 0.03(5)$ & $0.07 \pm 0.02(5)^{* *}$ & $0.85 \pm 0.25(4)$ & $0.22 \pm 0.07(4)$ \\
\hline $\mathrm{C}_{3}$ & $0.21 \pm 0.04(5)$ & $0.09 \pm 0.02(5)^{*}$ & $0.94 \pm 0.40(4)$ & $0 \cdot 30 \pm 0 \cdot 10(4)$ \\
\hline $\mathrm{C}_{2}$ & $0.29 \pm 0.06(5)$ & $0.15 \pm 0.04(5)^{* *}$ & $1.25 \pm 0.03(4)$ & $0.47 \pm 0.13(4)^{*}$ \\
\hline $\mathrm{C}_{1}$ & $0.29 \pm 0.01(5)$ & $0.13 \pm 0.04(5)^{*}$ & $1.04 \pm 0.22(4)$ & $0.44 \pm 0.17(4)^{* * *}$ \\
\hline First post-ovulatory follicle & $0.06 \pm 0.01(5)$ & $0.08 \pm 0.02(5)$ & $0.20 \pm 0.07(4)$ & $0.22 \pm 0.07(4)$ \\
\hline Rest of ovary & $0.04 \pm 0.10(5)$ & $0.07 \pm 0.01(5)$ & $0.19 \pm 0.07(4)$ & $0.18 \pm 0.04$ \\
\hline Infundibulum & $0.11 \pm 0.02(5)$ & $0.15 \pm 0.04(5)$ & $0.35 \pm 0.10(4)$ & $0.32 \pm 0 \cdot 10(4)$ \\
\hline Magnum & $0.11 \pm 0.02(5)$ & $0.16 \pm 0.03(5)$ & $0.48 \pm 0.19(4)$ & $0.32 \pm 0.10(4)$ \\
\hline Isthmus & $0.11 \pm 0.03(5)$ & $0.11 \pm 0.03(5)$ & $0.30 \pm 0.08$ & $0.21 \pm 0.05$ \\
\hline Uterus & $0.11 \pm 0.02(5)$ & $0.25 \pm 0.04(5)^{*}$ & $0.66 \pm 0.19(3)$ & $0.69 \pm 0.02$ \\
\hline
\end{tabular}

Values are mean \pm s.e.m. for the number of observations in parentheses.

Values significantly different from pre-treatment value (paired $t$ test): ${ }^{*} P<0.05 ;{ }^{* *} P<0.01 ;{ }^{* * *} P<0.001$.

\section{Discussion}

These results indicate considerable variation of blood flow within the ovary of the hen with stage of follicular maturation. The high blood flow to the major follicles could be related to the delivery of yolk precursors for deposition, since Redshaw \& Follett (1972) have suggested that yolk is deposited at a rate of $150 \mathrm{mg}$ protein/h. The great majority of this yolk is probably being deposited in the major pre-ovulatory follicles. Approximately $96.6 \mathrm{ml}$ blood will be delivered to the five major follicles in $1 \mathrm{~h}$ and this will supply about $150 \mathrm{mg}$ protein, this representing about $15 \%$ of the circulating concentration of yolk precursor (lipovitellin) $(1.0 \mathrm{~g} / 100 \mathrm{ml}$ blood) (Redshaw \& Follett, 1972). The blood flow to the major follicles also supplies essentials such as nutrients and oxygen for steroidogenesis by the follicles (Huang, Kao \& Nalbandov, 1979).

The difference in blood flow between the largest $\left(C_{1}\right)$ pre-ovulatory follicle and the first post-ovulatory follicle is particularly interesting. The post-ovulatory follicle is what is left of the largest $C_{1}$ follicle following ovulation and loss of the ovum. The maximum time for the conversion of the $\mathrm{C}_{1}$ follicle to a post-ovulatory follicle is approximately $24 \mathrm{~h}$. Obviously, the post-ovulatory follicle does not require yolk precursors. In addition, steroidogenesis in the post-ovulatory follicle is very low compared with that in the $C_{1}$ pre-ovulatory follicle (Dick, Culbert, Wells, Gilbert \& Davidson, 1978; Huang et al., 1979), and hence has low nutrient and oxygen requirements. This decreased steroidogenesis could be induced by the haemodynamic changes. The observed inhibition of blood flow to the major follicles after PGF- $2 \alpha$ treatment is similar to the effect of PGF-2 $\alpha$ on luteal blood flow in mammals (see 'Introduction' for references) and also to the difference between blood flow to the pre-ovulatory $\left(\mathrm{C}_{1}\right)$ and post-ovulatory follicle. The PGF-2 $\alpha$ synthesized by the $\mathrm{C}_{1}$ follicle at the time of ovulation (Day \& Nalbandov, 1977; Hammond et al., 1981a) could reduce blood flow to the follicle and in turn 
lead to decreased steroidogenesis: PGF- $2 \alpha$ would be an ideal factor, produced and active locally, to exert the changes necessary for the transition of the follicle to the post-ovulatory phase.

The data on cardiac output in the present study $(351 \pm 41 \mathrm{ml} / \mathrm{min}, \mathrm{N}=11)$ are very similar to those of Sturkie (1976) $(345 \mathrm{ml} / \mathrm{min})$ and the present results are qualitatively similar to those for follicular blood flow per unit weight reported by Wolfenson et al. (1978). Any quantitative differences could be accounted for by the different routes of administration of the radioactive microspheres. In the present study, spheres were injected via the intraventricular route, whereas, Wolfenson et al. (1978) injected spheres into the root of the aortic arch. The lower values for blood flow reported here (Table 4) may reflect differences in the mixing of the radioactive spheres with the blood. Blood flow to the shell-gland/uterus was markedly lower in this study $(0.66 \mathrm{ml} / \mathrm{min} / \mathrm{g})$ (Table 4) than in that of Boelkins, Muller \& Hall (1973) $(2 \mathrm{ml} / \mathrm{min} / \mathrm{g})$. However, in the latter study, the shell gland was actively calcifying an egg shell whereas in the present investigation, the shell gland was not calcifying and was therefore largely inactive.

This work was supported by the New Jersey State Experimental Station. We thank Doris Danko for help in some of the experiments.

\section{References}

Boelkins, J.N., Muller, W.J. \& Hall, K.L. (1973) Cardiac output distribution in the laying hen during shell formation. Comp. Biochem. Physiol. 46A, 735-743.

Day, S.L. \& Nalbandov, A.V. (1977) Presence of prostaglandin $F$ (PGF) in hen follicles and its physiological role in ovulation and oviposition. Biol. Reprod. 16, 486-494.

Dick, H.R., Culbert, J., Wells, J.W., Gilbert, A.B. \& Davidson, M.F. (1978) Steroid hormones in the post-ovulatory follicle of the domestic fowl. $J$. Reprod. Fert. 53, 103-107.

Hammond, R.W., Olson, D.M., Frenkel, R.B., Biellier, H.V. \& Hertelendy, F. (1981a) Prostaglandins and steroid hormones in plasma and ovarian follicles during the ovulation cycle of the domestic fowl (Gallus domesticus). Gen. comp. Endocr.42, 195-202.

Hammond, R.W., Koelkebeck, K.W., Scanes, C.G., Biellier, H.V. \& Hertelendy, F. (1981b) Plasma prostaglandin, $\mathbf{L H}$ and progesterone levels during the ovulation cycle of the turkey (Meleagris gallopavo). Gen. comp. Endocr. 44, 400-403.

Huang, E.S.-R., Kao, K.J. \& Nalbandov, A.V. (1979) Synthesis of sex steroids by cellular components of chicken follicles. Biol. Reprod. 20, 454-461.

Merrill, G.F., Russo, R.E. \& Halper, J.M. (1981) Cardiac output distribution before and during endotoxemia in the domestic fowl, Gallus domesticus. Am. J. Physiol. (in press).

Nett, T.M., McClellan, M.C. \& Niswender, G.D. (1976) Effects of prostaglandins on the ovine corpus luteum: blood flow, secretions of progesterone and morphology. Biol. Reprod. 15, 66-78.

Niswender, G.D., Reimers, T.J., Diekman, M.A. \& Nett,
T.M. (1976) Blood flow: a mediator of ovarian function. Biol. Reprod. 14, 64-81.

Novy, M.J. \& Cook, M.J. (1973) Redistribution of blood flow by prostaglandin $\mathrm{F}_{2 \alpha}$ in the rabbit ovary. Am.J. Obstet. Gyn. 117, 381-385.

O'Shea, J.D., Nightingale, M.G. \& Chamley, W.A. (1977) Changes in small blood vessels during cyclical luteal regression in sheep. Biol. Reprod. 17, 162-177.

Pharriss, B.B., Cornette, J.C. \& Gutknecht, G.D. (1970) Vascular control of luteal steroidogenesis. J. Reprod. Fert., Suppl. 10, 97-103.

Redshaw, M.R. \& Follett, B.K. (1972) The physiology of egg yolk production in the hen. In Egg Formation and Production, pp. 35-49. Eds B. M. Freeman \& P. E. Lake. British Poultry Science, Edinburgh.

Sturkie, P.D. (1976) Avian Physiology. Springer-Verlag, Berlin.

Varga, B. \& Folly, G. (1977) Effects of prostaglandins on ovarian blood flow in the bitch. J. Reprod. Fert. 51, 315-319.

Wehrenberg, W.B., Dierschke, D.J., Rankin, J.H.G. \& Wolf, R.C. (1978) Variations in "functional" blood flow as related to corpus luteum activity in cyclic guinea pigs. Biol. Reprod. 19, 380-384.

Wehrenberg, W.B., Dierschke, D.J. \& Wolf, R.C. (1979) The effect of prostaglandin $\mathrm{F}_{2 \alpha}$ on ovarian blood flow and progesterone concentrations in cyclic guinea pigs. Biol. Reprod. 21, 187-191.

Wolfenson, D., Berson, A., Frei, Y.F. \& Snapir, N. (1978) Measurement of flow distribution by radioactive microspheres in the laying hen (Gallus domesticus). Comp. Biochem. Physiol. 61A, 549554. 